\title{
Mapping the Spatial Variation of Soil Water Content at the Field Scale with Different Ground Penetrating Radar Techniques
}

L. Weihermüller, J.A. Huisman, S. Lambot, M. Herbst and H. Vereecken

Forschungszentrum Jülich GmbH, ICG-IV Agrosphere, 52425 Jülich, Germany, Tel.: +49-2461-618669,

e-mail: 1.weihermueller@fz-juelich.de 


\begin{abstract}
Two ground-penetrating radar (GPR) techniques were used to estimate the shallow soil water content at the field scale. The first technique is based on the ground wave velocity measured with a bistatic impulse radar connected to $450 \mathrm{MHz}$ ground-coupled antennas. The second technique is based on inverse modeling of an off-ground monostatic TEM horn antenna in the 0.8 to $1.6 \mathrm{GHz}$ frequency range. Data were collected on a 8 by $9 \mathrm{~m}$ partially irrigated intensive research plot and along four $148.5 \mathrm{~m}$ transects. Time domain reflectrometry, capacitance sensors, and volumetric soil samples were used as reference measurements. The aim of the study was to test the applicability of the ground wave method and the off-ground inverse modeling approach at the field scale for a soil with a silt loam texture. The results for the ground wave technique were difficult to interpret due to the strong attenuation of the GPR signal, which was related to the silt loam texture at the test site. The root mean square error of the ground wave technique was $0.076 \mathrm{~m}^{3} \mathrm{~m}^{-3}$ when compared to the TDR measurements and $0.102 \mathrm{~m}^{3} \mathrm{~m}^{-3}$ when compared with the volumetric soil samples. The off-ground monostatic GPR measured less within field soil water content variability than the reference measurements, resulting in a root mean square error of $0.053 \mathrm{~m}^{3} \mathrm{~m}^{-3}$ when compared with the TDR measurements and an error of $0.051 \mathrm{~m}^{3} \mathrm{~m}^{-3}$ when compared with the volumetric soil samples. The variability between the two GPR measurements was even larger with a RSME of $0.115 \mathrm{~m}^{3} \mathrm{~m}^{-3}$. In summary, both GPR methods did not provide adequate spatial information on soil water content variation at the field scale. The main reason for the deviating results of the ground wave method was the poor data quality due to high silt and clay content at the test site. Additional reasons were shallow reflections and the dry upper soil layer that cannot be detected by the ground wave method. In the case of off-ground GPR, the high sensitivity to the dry surface layer is the most likely reason for the observed deviations. The off-ground GPR results might be improved by using a different antenna that allows data acquisition in a lower frequency range.
\end{abstract}

Keywords: GPR, ground wave, off-ground, TDR, soil water content, field scale 


\section{Introduction}

Knowledge of the shallow subsurface hydrogeophysical properties, including surface and subsurface water content, is essential in the fields of agricultural and environmental engineering, ground water hydrology, meteorology, soil landscape modeling, and soil physics. Surface soil water content defines the boundary condition of important processes, such as infiltration, runoff, and evaporation. In general, soil water content is highly variable in space and time. Spatial variability of soil water content is affected by both small scale variability in soil hydraulic properties at the centimeter scale (Ritsema and Dekker, 1998) and large scale variability at the kilometer scale (Jackson and Le Vine, 1996). Additionally, lateral water redistribution varies at scales from meters to several hundreds of meters under the influence of topography (Western et al., 1998), and water redistribution by vegetation (Bouten et al., 1992; Hupet and Vanclooster, 2002). Disregarding the spatial variability of soil water content may contribute significantly to errors in many predictions, e.g. for infiltration, and surface runoff (Merz and Bardossy, 1998; Pauwels et al., 2001), crop yield, flood control (Schlesinger et al., 1990), and meso-scale transpiration loss (Wood, 1997).

Point information on soil water content can be obtained using different techniques, like Time Domain Reflectrometry (TDR), capacitance sensors, or volumetric sampling. In general, the application of all these techniques is restricted to small observation areas and is generally too time-consuming for soil water content mapping of larger areas (Western and Grayson, 1998). Furthermore, these techniques may disturb the soil structure, prohibiting accurate in situ soil water content measurements (Lunt et al., 2005). On the other hand, remote sensing provides an effective methodology for mapping surface soil water content over large areas (Cognard et al., 1995, D'Urso and Minacapilli, 2006). The disadvantage of most remote sensing techniques is the low temporal resolution and the fact that the measurement averages withinpixel variability and therefore masks the underlying heterogeneity observed at the land surface (Famiglietti et al., 1999). An even more important disadvantage of remote sensing is the shallow measurement depth and the inability to observe the soil water content when dense vegetation is present (Ulaby et al., 1996).

Clearly, there is a gap between remote sensing and point measurements of soil water content. At intermediate spatial scales, such as agricultural fields or small catchments, reliance on sparse point measurements or coarse remote sensing data might not provide the accurate soil water content information required at these scales (e.g. for irrigation, precision farming, crop management, erosion control). Therefore, there is a need for soil water content measurement techniques that can provide dense and accurate measurements at this intermediate scale with a high temporal resolution.

To investigate the relationship between field scale (effective) fluxes of water, energy, and carbon dioxide and the spatial variations of these fluxes within the field, the FLOWatch test site has been established. The within-field variability of these fluxes is strongly related to the spatial variation of soil water content. Therefore, a range of soil water content measurement techniques are investigated within the FLOWatch project. During the last years, Ground Penetrating Radar (GPR) methods have shown promise for estimating soil water content at the field scale (van Overmeeren et al., 1997; Weiler et al., 1998; Bohidar and Hermance, 2002, Davis and Annan, 2002; Grote et al., 2003; Huisman et al., 2003a; Galagedara et al., 45 2005; Wollschläger and Roth, 2005). The advantage of GPR methods is that they provide a means to monitor large areas and soil volumes relatively quickly and cost-effectively, and therefore, may bridge the gap between point information and remote sensing data.

In general, three different approaches are available to map soil water content with GPR. The first approach is based on the analysis of reflected waves (van Overmeeren et al., 1997; 
Weiler et al., 1998; Huisman et al., 2003a; Lunt et al., 2005; Wollschläger and Roth, 2005). This method requires knowledge of the depth of the reflection for absolute soil water content calculations and is, therefore, less suited for mapping of surface soil water content. The second method is based on the analysis of the ground wave velocity ( $\mathrm{Du}$ and Rummel, 1996; Huisman et al., 2001; Hubbard et al., 2002; Grote et al., 2003; Huisman et al., 2003b). In general, the ground wave is the part of the radiated energy that travels between the transmitter and receiver through the top of the soil. The third approach is based on analyzing the (sub-) surface reflections of an off-ground GPR system, as described by Davis and Annan (2002), Redman et al. (2002) and Lambot et al. (2004a, 2004b, 2006a) amongst others. The advantage of the monostatic off-ground GPR method proposed by Lambot et al. (2004a, 2004b, 2004c, $2006 \mathrm{a}$ ) is the possibility of a full wave inversion of the radar signal which takes into account the antenna effects and does not require an antenna height specific calibration above a perfect electric conductor (PEC, e.g. a metal plate). In general, the antenna elevation above the soil inherently varies during field experiments, which may lead to significant errors using the traditional off-ground methods. In our study, the ground wave approach and the monostatic off-ground approach were tested on a field site where both texture and soil water content are highly variable.

In contrast to the ground wave technique, the monostatic off-ground GPR methodology was used for the first time to monitor soil water content at the field scale. Both methods were compared with reference measurements obtained with Time Domain Reflectrometry (TDR) or capacitance sensors, and volumetric soil samples in two measurement campaigns.

The aim of this study was to test the applicability of the off-ground GPR and ground wave GPR method at the field scale to monitor soil water content of environmentally relevant soil depths (e.g. $0-5$ or $0-10 \mathrm{~cm}$ ), The soil water content of this shallow upper soil layer is relevant for flood control, soil erosion protection, $\mathrm{CO}_{2}$ production, and plant water availability.

\section{Materials and Methods}

\subsection{FLOWatch test site}

The FLOWatch test site of the Forschungszentrum Jülich GmbH is situated in the southern part of the Lower Rhine Embayment in Germany. The underlying sediments are Quaternary sediments, which are mostly fluvial deposits from the Rhine/Meuse river and the Rur river system, covered by eolian sediments (up to a depth of $1 \mathrm{~m}$ ) from the Pleistocene and Holocene. The test site is weakly inclined $\left(<4^{\circ}\right)$ in east-west direction (Fig. 1). In the lower part of the test site, colluvial sediments eroded from the upper part can be found. The ground water depth shows seasonal fluctuations between $3-5 \mathrm{~m}$ below the surface. The major soil type is silt loam according to the USDA textural classification. In the upper part of the test site, the uppermost $30 \mathrm{~cm}$ of the soil contains $35 \%$ sand, $52 \%$ loam, and $13 \%$ clay, compared to $13 \%$ sand, $70 \%$ loam, and $17 \%$ clay in the lower part of the field. Due to the geomorphology and soil texture variation, a high variability in the surface soil water content is present. In general, the upper part of the test site shows lower surface soil water contents compared to the lower part. The experimental field plot $(15 \times 15 \mathrm{~m})$ is situated in the lower part of the test site (see Fig. 1).

\subsection{GPR and reference measurements}


Following the approach of Lambot et al. (2004a, 2004b, 2004c, 2005), an ultra wideband stepped-frequency continuous-wave radar combined with an off-ground monostatic transverse electromagnetic (TEM) horn antenna (BBHA 9120 A, Schwarzbeck Mess-Elektronik, Schönau, Germany) was used. The radar system was set up using a Vector Network Analyzer (VNA) (FSH6 equipped with a VSWR bridge and power provider, Rohde \& Schwarz, Munich, Germany) connected to an antenna system consisting of a linear polarized doubleridged broadband TEM horn. The antenna dimensions are $0.22 \mathrm{~m}$ in length and a $0.14 \mathrm{x} 0.24$ $\mathrm{m}^{2}$ aperture area. The nominal frequency range was $0.8-1.8 \mathrm{GHz}$. Measurements were performed with the antenna aperture situated at heights from 0.36 to $0.46 \mathrm{~m}$ above ground. The VNA was calibrated at the connection between the antenna feed point and the high quality $\mathrm{N}$ type $50 \Omega$ impedance coaxial cable of $2.5 \mathrm{~m}$ length using a $50 \Omega$ OSM (Open, Short, Match) series of a high precision standard calibration kit (ZVZ21-N, Rohde \& Schwarz, Munich, Germany).

The transfer function describing the monostatic off-ground GPR system, expressed in the frequency domain, is given by Lambot et al., 2004b:

$$
S_{11}(\omega)=\frac{b(\omega)}{a(\omega)}=H_{i}(\omega)+\frac{H(\omega) G_{x x}^{\uparrow}(\omega)}{1-H_{f}(\omega) G_{x x}^{\uparrow}(\omega)}
$$

where $b(\omega)$ and $a(\omega)$ are, respectively, the received and emitted signals at the VNA reference plane, $H_{i}(\omega)$ is the antenna return loss, $H(\omega)=H_{t}(\omega) H_{r}(\omega)$ is the antenna transmittingreceiving transfer function, $H_{f}(\omega)$ is the antenna feedback loss, and $G_{x x}^{\uparrow}(\omega)$ is the transfer Green's function of the air-subsurface system modeled as a three-dimensional multilayered medium. In general, the off-ground GPR measurements are performed in the frequency domain. Knowledge of the antenna properties $H(\omega), H_{i}(\omega)$, and $H_{f}(\omega)$ permits to remove the antenna effects from the $S_{11}(\omega)$ function and to calculate $G_{x x}^{\uparrow}$, which describes the response of the soil layers. In a next step, the frequency domain signal is transformed into the time domain by Inverse Fast Fourier Transformation (IFFT). The resulting time domain measurement is analyzed. A full description of the modeling of the radar signal is given by Lambot et al. (2004a, 2004b, 2005). Due to the poor raw data quality in the higher frequency range, which might be caused by surface roughness, the fitting procedure using inverse simulation was performed on the frequency window of 800 to $1600 \mathrm{MHz}$ only.

For the ground wave method, the procedures described by Huisman et al. (2003a, 2003b) and Galagedara et al. (2005) were used. The first step in the ground wave method is the acquisition of a set of Wide Angle Reflection and Refraction (WARR) measurements. In WARR acquisition, the distance between the antennas is increased stepwise with the transmitter at a fixed position. These WARR measurements are used to determine the optimal distance between antenna and receiver (see below). In a second step, the GPR measurements are performed with this optimal antenna separation (see section 3.2). The ground wave velocity $v$ can be calculated by dividing the travel distance (antenna separation) $x$ by the measured ground wave travel time $\left(v=x / t_{G W}\right)$. However, since the bistatic GPR systems do not have a fixed zero-time, the ground wave velocity must be calculated from the difference in arrival time between the air wave and the ground wave. The relationship between ground wave arrival time $t_{G W}[\mathrm{~s}]$, antenna separation $x[\mathrm{~m}]$, and soil permittivity $\varepsilon_{\text {soil }}$ then becomes

$$
\varepsilon_{\text {soil }}=\left(\frac{c}{v}\right)^{2}=\left(\frac{c\left(t_{G W}-t_{A W}\right)+x}{x}\right)^{2}
$$


where $t_{A W}[\mathrm{~s}]$ is the air wave arrival time and $c\left[3.010^{8} \mathrm{~ms}^{-1}\right]$ the speed of light in free space (Huisman et al., 2003a). In this study, a pulseEKKO1000 system (Sensors and Software Inc., Toronto, Canada) with $225 \mathrm{MHz}$ and $450 \mathrm{MHz}$ antennas was used.

As reference measurements of the soil water content, Time Domain Reflectrometry (TDR), capacitance sensors (Theta probe), and undisturbed soil samples (100 or $300 \mathrm{~cm}^{3}$ volumetric samples) were used. All TDR measurements were made using a Campbell Scientific TDR 100 system (Campbell Scientific Inc., Logan, Utah, USA) with a custom-made 3-wire probe of $0.10 \mathrm{~m}$ length. The capacitance sensor was a $0.06 \mathrm{~m}$ long probe (ML2x, DeltaT Devices Ltd., UK), from which only the millivoltage signal was stored and converted to dielectric permittivity afterwards. The RMS error of the capacitance probe is approximately $0.03 \mathrm{~m}^{3} \mathrm{~m}^{-3}$ (Evett and Steiner, 1995), and the sampling interval $(0-0.06 \mathrm{~m})$ is smaller than the TDR probe but larger than the undisturbed soil sample (depth is $0-0.03 \mathrm{~m}$ for the $100 \mathrm{~cm}^{3}$ and 0 $0.05 \mathrm{~m}$ for the $300 \mathrm{~cm}^{3}$ rings). The calculation of the volumetric water content from the dielectric permittivity measured with GPR, TDR, and the Theta probe was based on Topp's equation (Topp et al., 1980). The volumetric water content of the undisturbed soil samples was obtained by oven drying at $105^{\circ} \mathrm{C}$ for $48 \mathrm{~h}$.

For the GPR feasibility study, two measurement campaigns took place: the first one on $21^{\text {st }}$ of March 2005 and the second one on $27^{\text {th }}$ of July 2005. For the first campaign, the intensive research plot was plowed to a depth of $0.15 \mathrm{~m}$ and compacted afterwards using a $0.5 \mathrm{~m}$ long roller to reduce soil roughness. Because of the low natural spatial variation in soil water content of this small research plot, one part ( 3 by 3 meter in the upper right corner) of the test plot was irrigated manually to create a wider range in soil water content. From visual observations, irrigation did not change the soil density or soil roughness. This is mainly due to the fact that the entire plot was smoothed and compacted before starting the experiment. Offground GPR measurements were performed every meter, resulting in 72 radar measurements. The antenna height was fixed at $0.3 \mathrm{~m}$ above the ground. Before the measurements were made, the off-ground GPR system was calibrated using a perfect electric conductor. After each radar measurement, five juxtaposed Theta probe measurements were performed in the soil just below the antenna for measuring the soil reference dielectric permittivity (measurement depth $=0.06 \mathrm{~m}$ ). In addition, three $100 \mathrm{~cm}^{3}$ undisturbed soil samples were extracted for each measurement location in every other line, resulting in 36 direct measurements of the volumetric soil water content. For the Theta probe and the volumetric water content measurements, averaged values for each measurement point were considered.

For the second measurement campaign, four transects were measured along the EW axis of the test site with a spacing of 8 meters. To reduce soil roughness, the field was tilled to a depth of $0.15 \mathrm{~m}$ and compacted several days afterwards using a 2 ton roller. Changes in volumetric soil water content caused by using the roller were accepted in the field experiment because all methods were equally affected. Each transect contains 12 measurement points. At each of these measurement points, monostatic off-ground GPR measurements and three TDR measurements were taken. Thus, 48 measurement points were sampled with TDR and offground GPR. Three $300 \mathrm{~cm}^{3}$ volumetric samples were taken at every second measurement point (24 in total). The off-ground GPR system was mounted on a wooden frame in front of a tractor. For the ground wave method, the GPR transmitter and receiver were installed on sleds, which were pulled by the tractor. Ground wave measurements were taken every $0.5 \mathrm{~m}$ by triggering the GPR system with an odometer. This resulted in 1188 ground wave measurement points. The spacing between the antenna and receiver was fixed at $1.18 \mathrm{~m}$. The optimal separation between antenna and receiver was obtained from preliminary WARR measurements along a $60 \mathrm{~m}$ transect. 
In this study, we chose to use two different types of reference measurements in each experiment: one method that determines the dielectric permittivity (capacitance sensor in the first experiment and TDR in the second experiment) and volumetric soil samples. This choice was motivated by practical reasons. Volumetric soil samples are very cumbersome to take, especially when the size fraction $>2 \mathrm{~mm}$ is significant. Because several volumetric soil samples were required per sampling point in order to get an estimate at the scale of the GPR measurements, we decided to only take volumetric samples at every other sampling point. Because dielectric permittivity measurements are easier to make, we used these methods as a second reference. Previous studies have shown that volumetric samples and TDR or capacitance measurements gave similar results (e.g. Huisman et al., 2001; Lunt et al., 2005). The difference in sampling depth between the reference measurements was also motivated by practical considerations. Again, it is cumbersome to take volumetric soil samples up to a depth of $0.10 \mathrm{~m}$. In contrast, a practical minimum length of TDR probes is $\sim 0.10 \mathrm{~m}$. Finally, it is also not feasible to take shallower volumetric samples (e.g. $0-0.01 \mathrm{~m})$. Alternatively, it would have been possible to determine the gravimetric water content (e.g. gram water per gram soil) of this shallow upper layer. However, to convert the gravimetric water content to volumetric water content (the soil property sensed by electromagnetic methods) information on the dry bulk density of the upper layer is required. Such information is not available at the field scale.

\section{Results and Discussion}

\subsection{Plot measurements}

The calculated soil water content from the off-ground GPR and the Theta probe measurements from the first measurement campaign are plotted in Fig. 2. In general, the dielectric permittivity, and the calculated soil water content using Topp's equation (Topp et al. 1980), was lower for the off-ground GPR than for the Theta probe. As Lambot et al. (2005, 2006b) already stated, this behavior can be partly attributed to the effect of soil roughness on the amplitude of the surface reflection. Another reason might be the vertical distribution of the soil water content. The Theta probe gives average values up to a depth of $0.06 \mathrm{~m}$, whereas the off-ground GPR provides values for which the depth of influence varies as a function of soil water content and the soil water content profile, and is therefore not precisely known. During the experiment, the soil water content profile was characterized by an upper drier layer of $\sim 0.015 \mathrm{~m}$ at the non-irrigated measurement points due to soil evaporation. Therefore, the lower soil water content estimates obtained with the off-ground GPR system might be explained by the fact that this method is mainly sensitive to the upper part of the soil in the frequency range of 0.8 to $1.8 \mathrm{GHz}$. For instance, Serbin and Or (2004) showed that surface reflection GPR measurements were in good agreement with volumetric measurements for the top $0.01 \mathrm{~m}$ layer of soil, but did not agree well with deeper TDR and gravimetric data. This explanation was confirmed by the fact that for the higher soil water contents, pertaining to the irrigated area which did not exhibit the dry surface layer, off-ground GPR and Theta probe 


\subsection{Field measurements}

\subsubsection{Preliminary WARR measurements}

To find the optimal distance between antenna and receiver, a transect of $60 \mathrm{~m}$ was measured

in the middle of the field. Along this transect, 20 WARR measurements with a maximum antenna separation of $3 \mathrm{~m}$ and a step size of $0.1 \mathrm{~m}$ were performed with $225 \mathrm{MHz}$ and 450 $\mathrm{MHz}$ shielded antennas. Figure 3 shows four WARR measurements obtained with the 450 $\mathrm{MHz}$ antenna along the $60 \mathrm{~m}$ transect. In general, the four WARR measurements appear quite different. In the first WARR radargram (Fig. 3a) measured between $0-3 \mathrm{~m}$, the air wave, the ground wave and several reflected waves can be distinguished. However, the ground wave can be only recognized between an antenna separation of 0.5 and $1.5 \mathrm{~m}$. At larger antenna separations a clear interference with a very shallow reflected wave that starts at $15 \mathrm{~ns}$ is detectable. In the second WARR measurement ( 9 - 12 m, Fig. 3b), the signal attenuation clearly increased. The ground wave can only be detected up to an antenna separation of $1.8 \mathrm{~m}$. The interference with a shallow reflected wave cannot be recognized anymore. However, several critically refracted waves appeared. Critically refracted waves can be recognized as waves parallel to the air wave but at later times. In the third WARR measurement $(18-21 \mathrm{~m}$, Fig. 3c), the signal attenuation has further increased and the ground wave can only clearly be recognized up to an antenna separation of $1.3 \mathrm{~m}$. Finally, in the fourth WARR measurement (27-30 m, Fig. 3d), the attenuation has increased up to a level were the ground wave cannot be recognized anymore in the radargram. Instead, only the air wave and several critically refracted waves can be seen. Not all remaining WARR measurements of the $60 \mathrm{~m}$ transect were as difficult to interpret as the WARR measurements shown in the lower right of Fig. $3 \mathrm{~d}$. However, high attenuation was prevalent and the ground wave was difficult to recognize in some WARR measurements. After careful inspection of all data, an antenna separation of 1.2 $\mathrm{m}$ was selected for soil water content mapping, although the complexity of the WARR measurements in Fig. 3 suggested that considerable problems in the interpretation of the fixed-offset ground wave GPR measurements were to be expected.

The WARR measurements made with the $225 \mathrm{MHz}$ antennas showed a similar behavior (results not shown). However, the interference with shallow reflected waves was stronger because of the lower resolution at lower frequencies. Therefore, the $450 \mathrm{MHz}$ antennas were selected for soil water content mapping along the four transects.

\subsubsection{Ground wave GPR}

Figure 4 shows two of the four ground wave GPR profiles, where the horizontal wave at approximately $14 \mathrm{~ns}$ corresponds with the air wave. Typically, it is assumed that the ground wave is the next arrival in the radargram. In the upper GPR profile (Transect 1 ) between 20 and $50 \mathrm{~m}$, a clear wave can be recognized. From the preliminary WARR measurements, this wave was identified as the ground wave. The arrival time of the ground and the air wave were picked to calculate the permittivity according to Eq. 2. Figure 4 also shows that the ground wave is difficult to recognize in large parts of the GPR profile. Especially between 50 and 150 $\mathrm{m}$ in Transect 4 (lower GPR profile) no clear signal from the soil is detectable. Although there is a strong attenuated signal between 20 and $25 \mathrm{~ns}$ that we interpreted as the ground wave, the similarity with a similar feature between 18 and 20 ns could also indicate that the radargram is dominated by multiple critically refracted waves in this part of the profile. The soil water content measured by the ground wave method at the field scale along the four transects is plotted in Fig. 5. The soil water content calculated by the ground wave method varied from 0.126 to $0.286 \mathrm{~m}^{3} \mathrm{~m}^{-3}$ in the upper and lower part, respectively. In general, a slight trend in the soil water content is visible with lower soil water contents in the upper part and higher soil water contents in the lower part. 


\subsubsection{Off-ground GPR}

An example of measured and fitted windowed time domain Green's function $G_{x x}^{\uparrow}(\omega)$ for two measurement points (Point 14 (Transect 2) and Point 22 (Transect 2)) are shown in Fig. 6. In the analysis, the reflection of the surface is automatically detected in the time domain and serves to determine the time window in which the inversion was performed. Figure 6a shows that the measurement at Point 14 (Transect 2) is accurately reproduced by the electromagnetic model, whereby the electromagnetic model for the measurement at Point 22 (Transect 2, Fig. $6 \mathrm{~b})$ shows perceptible deviations between the model and the measurement. The origin of the observed discrepancies is twofold. First, the solution is quite sensitive to actual measurement and modeling errors. But as shown in Lambot et al. (2004b), these errors are quite small. Second, the water content in the top layer might not have been sufficiently homogeneous and, consequently, the measured and modeled time domain Green's functions deviate because the model assumes a homogeneous soil.

Figure 7 presents the time domain Green's function for the 48 measurement points along the four transects. The Green's function is computed from the $S_{11}(\omega)$ scatter function using Eq. 1 . Time zero corresponds to the antenna phase center. The soil surface reflection occurrs at different times ( 2 to $3 \mathrm{~ns}$ ) due to the inherently varying antenna height above the ground. Additionally, no significant reflectors below the soil surface can be distinguished (times $>4$ ns). This is mainly due to the high operating frequency range used in the experiment and the limited electromagnetic wave penetration depth in the silt-loam soil. The slight ripples on the time domain signal are caused by the inverse Fourier transformation, since only the signal frequencies between 800 - $1600 \mathrm{MHz}$ were analyzed.

For the first measurement in Transect 1 (Fig. 7), the amplitude of the signal around time zero is small, then it increases progressively until Measurement 24 (lower part of Transect 2). This evolution is partly due to the effect of temperature on the calibration of the VNA. Variations $>5^{\circ} \mathrm{C}$ are expected to distort significantly the system calibration. In that respect, it is worth noting that these variations are automatically detected by the VNA. In addition, variations of the surface reflection may also lead to some variations of the amplitude at early times because some correlation always exists between the signals at two different times relatively close to each other, due to the inverse Fourier transform of a limited frequency range signal. Then, prior to Measurement 25 (start of Transect 3), the VNA was subjected to a new OSM calibration. As a result, the amplitude of the signal at early times became smaller, which indicates that the measurement errors were small again. A new calibration was also performed between Measurement 44 and 45 (lower part of Transect 4), which led to the same observation. The results for the calculated soil water content measured by the off-ground GPR method at the field scale are plotted in Fig. 5. The soil water content calculated by the offground GPR method varied between 0.043 and $0.163 \mathrm{~m}^{3} \mathrm{~m}^{-3}$ in the upper and lower part, respectively. Only a weak trend in the soil moisture content is observed with lower soil moisture contents at the upper part and higher soil moisture contents in the lower part.

\subsubsection{Reference measurements}

It can be seen that the maps based on the TDR measurements and the volumetric water content samples both show a similar trend in soil water content (Fig. 5) with lower volumetric soil water contents at the upper part of the test site and higher once at the lower part. The range of soil water content varies between $0.079 \mathrm{~m}^{3} \mathrm{~m}^{-3}$ and $0.186 \mathrm{~m}^{3} \mathrm{~m}^{-3}$ for the volumetric samples and between $0.071 \mathrm{~m}^{3} \mathrm{~m}^{-3}$ and $0.200 \mathrm{~m}^{3} \mathrm{~m}^{-3}$ for the TDR measurements. For a more detailed comparison, the volumetric soil water contents calculated from volumetric samples and TDR are plotted against each other in Fig. 8c. The plot indicates that the undisturbed soil samples show slightly higher soil water contents at the lower moisture range, whereby the TDR probe underestimates the soil water content in the higher range. The Root Mean Square 
Error (RMSE) between these methods is low (see Tab. 1) with a value of $0.021 \mathrm{~m}^{3} \mathrm{~m}^{-3}$. This indicates that there is a good agreement with respect to small scale soil heterogeneity within the antenna footprint. The adequate relation between the reference measurements in Fig. 8c and Tab. 1 indicates that the use of the point measurements for the validation of the results from the two GPR systems was appropriate. In other words, the good correlation means that the soil water content integrated over 0 to 0.05 and 0 to $0.10 \mathrm{~m}$ are similar. It also means that the aggregation from the point scale to the antenna footprint scale was successful.

\subsection{Comparison of the measurement methods}

As shown in Fig. 5, the soil water content measurements based on the ground wave and the off-ground method deviate from the reference measurement techniques. This is confirmed by the high RSME of $0.1154 \mathrm{~m}^{3} \mathrm{~m}^{-3}$ between off-ground GPR and the ground wave method (Tab. 1). In general, the ground wave method seems to overestimate the water content over the entire field, whereas the off-ground method underestimates the soil moisture content and shows less variability. For a more detailed comparison of the results obtained from the two GPR methods and the reference measurements, the calculated volumetric soil water contents are plotted versus the results from $0.1 \mathrm{~m}$ TDR probes (Fig. 8a-b). Figure 8a clearly shows that the off-ground GPR technique underestimates the soil water content measured by TDR up to a depth of $0.10 \mathrm{~m}$. In contrast, the ground wave method overestimates the soil water content in the $0.10 \mathrm{~m}$ surface layer. This indicates that the off-ground GPR measurements are mostly influenced by the shallow surface layer which was exposed to evaporation during the field experiment. As Lambot et al. (2006a) already showed in their modeling exercise, layering of the soil with differences in soil water content may lead to absolute measurement errors on the dielectric permittivity in a range between 1 and 3 (corresponding to an error in soil water content of about 0.03 to $0.09 \mathrm{~m}^{3} \mathrm{~m}^{-3}$ ), depending on the frequency range and the depth of the chosen layers. This behavior is confirmed by the RSME of $0.053 \mathrm{~m}^{3} \mathrm{~m}^{-3}$ for the TDR probe and $0.051 \mathrm{~m}^{3} \mathrm{~m}^{-3}$ for the volumetric soil samples. Interestingly, the correlation between water content calculated from off-ground GPR measurements and volumetric soil samples shows a twofold behavior with a slightly higher correlation and a lower RMSE of $0.042 \mathrm{~m}^{3} \mathrm{~m}^{-3}$ for the measurement points along Transects 2 to 4 and a slightly lower correlation and a higher RMSE of $0.0711 \mathrm{~m}^{3} \mathrm{~m}^{-3}$ for the first transect (see also Fig. 8a). The sudden change in the correlation pattern is related to the poor quality of the off-ground raw data along the first points of the first transect which can be detected in the inverse modeling procedure. Due to the fact that all other points beyond measurement 12 show better agreement up to the OSM calibration at point 25 , it was assumed that an insufficient calibration can not be taken as the source of inaccuracy. A possible alternative explanation for the poorer data quality is a higher soil roughness at the field boundary or some unidentified problem in the data acquisition setup for the first measurements.

The reasons for the discrepancies between the off-ground GPR and reference measurements are multiple. First, off-ground GPR and TDR operate at different scales and depth. The operation area of a single TDR measurement is $\approx 20 \mathrm{~cm}^{2}$, and for the off-ground GPR $\approx 720$ $\mathrm{cm}^{2}$. Even if the TDR measurements were averages for three points, and the good correlation between the point averaged values of TDR and the volumetric soil samples indicate that the scale gap is properly bridged, depth differences seem to be relevant. The depth for the soil water content measurement of the off-ground GPR can be roughly approximated by: 


$$
\frac{\lambda_{\text {soil }}}{4}=\frac{\frac{v}{f}}{4}=\frac{\frac{c}{\sqrt{\varepsilon_{\text {soil }}}}}{\frac{\left(f_{1}+f_{2}\right) / 2}{4}}
$$

where $\lambda_{\text {soil }}$ is the radar wavelength, $v$ is the propagation velocity of the wave in the soil, $f$ is the frequency, $\varepsilon_{\text {soil }}$ is the dielectric permittivity of the soil, $f_{l}$ is the lowest used frequency, and $f_{2}$ is the highest used frequency (Lambot et al., 2006a). For instance, assuming a dielectric permittivity for dry soil of $\varepsilon_{\text {soil }}=4$ for our measurement setup, the depth of measurement will be $\sim 0.029 \mathrm{~m}$ and for $\varepsilon_{\text {soil }}=16$ (wet soil) the depth of measurement is $\sim 0.014 \mathrm{~m}$ for the center frequency. In comparison, the measurement depth of the volumetric soil samples was $0.05 \mathrm{~m}$ and the depth of the TDR measurements was $0.10 \mathrm{~m}$.

Finally, the off-ground GPR measurements are affected by several factors. Surface roughness (Lambot et al., 2006b) or stochastic heterogeneity of the soil electromagnetic properties may lead to diffuse reflection and scattering which are not accounted for by the inverse modeling procedure. The presence of such phenomena can partly explain the lower soil water contents measured with the off-ground GPR. Then, in addition to the radar calibration and measurements errors, the shallow soil stratigraphy and soil electric conductivity are also important characteristics which can play a significant role.

The volumetric soil water soil content measured with the ground wave GPR method was compared with TDR measurements. As shown in Fig. 8b, the ground wave method overestimates the soil water content measured by the $0.10 \mathrm{~m}$ TDR probe. Additionally, the RMSE is quite high with $0.076 \mathrm{~m}^{3} \mathrm{~m}^{-3}$ (Tab. 1). There are three possible reasons for the inadequate results of the ground wave method at the FLOWatch test site. The first and most important reason is the strong attenuation of the GPR signal in the lower part of the field. In general, attenuation is strongly related to soil water content and soil texture. As already stated by Huisman et al. (2001) and Doolittle et al. (2006), soils with high silt and clay content are not always suitable for GPR surveys, especially for the ground wave method. The second reason for the discrepancy of the ground wave measurements versus ground truth data is the possible interference of shallow reflections. There is no guarantee that these reflections will not arrive even earlier in different parts of the field depending on variation of the shallow reflecting layers. An indication for the interference with reflected waves is given by different ground wave signatures in the left part of the GPR profiles shown in Fig.4. Finally, the higher soil water content estimates obtained with the ground wave method could also be explained by a mismatch between the TDR sampling depth and the ground wave penetration depth. If the ground wave penetrated deeper than $0.10 \mathrm{~m}$ into the soil, it could have sampled layers with higher water contents. Unfortunately, the penetration depth for the ground wave method is still under debate. However, it has become clear that it varies from several $\mathrm{cm}$ to $\mathrm{dm}$ depending on the acquisition parameters, the operating radar frequency, and the soil permittivity (Galagedara et al., 2005). As Galagedara et al. (2005) showed in their electromagnetic modeling approach, the ground wave velocity also depends on the layering of the soil and the dielectric contrast between the layers. They clearly showed that a dry upper soil layer will not necessarily influence the ground wave. In general, the depth of an 'undetected' dry upper soil layer increases with a decrease of frequency. More explicitly, they showed that for an antenna frequency of $450 \mathrm{MHz}$, a dry soil layer of $0.08 \mathrm{~m}$ over a wet soil layer remains undetected (i.e. the ground wave velocity is determined by the water content of the wet layer below $0.08 \mathrm{~m}$ and does not represent and average of the top soil).

\section{Conclusions}


In general, the spatial variation in soil water content measured with the ground wave and offground method did not correspond with the variations measured with TDR and volumetric soil samples. The main reason for the failure of the ground wave method was the strong attenuation of the GPR signal, which is related to the texture at the test site. Shallow reflections and the dry upper soil layer might also have contributed to the poor correspondence between the ground wave method and the reference measurements. The variations in the off-ground GPR results as compared with the reference measurements might be explained by differences in the sampling volume and depth. The low variations in the offground GPR data may be attributed to the homogeneously dry upper soil layer. However, several issues are still to be investigated to better understand the various factors affecting the off-ground radar measurements (e.g. soil roughness, soil layering, and electrical conductivity). Therefore, laboratory experiments should be conducted and the results should be implemented into modeling approaches. Especially soil surface roughness and soil layering should be taken into account in the electromagnetic inverse modeling approach. Future work, using lower frequency antennas, might also overcome the problem of soil surface roughness for the off-ground GPR measurements, and therefore allow measurements under natural soil conditions without a priori smoothing of the soil surface. On the other hand, reliable and comparable ground truth measurements are necessary to compare the off-ground GPR results. Nevertheless, the off-ground GPR configuration used in this study was not suitable to monitor the soil water content of the upper $0-0.05 \mathrm{~m}$ layer, which is considered as an environmentally relevant depth for important processes, such as $\mathrm{CO} 2$ production and plant water availability. To overcome the problem of shallow measurement depths using off-ground GPR, lower frequencies should be used which allow deeper penetration into the soil profile.

The feasibility study of the two different GPR methods at the FLOWatch test site clearly showed that the ground wave method was not suitable for this site and that the off-ground method is not comparable with standard soil physical soil water content measurement techniques. Clearly, there is considerable need for a wider range of approaches to noninvasively map soil water content variation at the field scale.

\section{Acknowledgments}

We thank R. Harms, H.G. Sittardt, and T. Pütz for their assistance with the measurements. We also want to thank the University of Amsterdam for the 'ground wave GPR' system. Finally we wish to thank the two anonymous reviewers, whose insightful suggestions improved the focus and organization of this manuscript. 


\section{References}

Bohidar, R.N., Hermance, J.F., 2002. The GPR refraction method. Geophysics 67, 160-172 Bouten, W., Heimovaara, T.J., Tiktak, A., 1992. Spatial patterns of throughfall and soil water dynamics in a Doughlas fir stand. Water Resources Research 28, 3227-3233

Cognard, A.L., Loumagne, C., Normand, M., Olivier, P., Ottlé, C., Vidal-Madjar, D., Louahala, S., Vidal, A., 1995. Evaluation of the ERS1/synstetic aperture radar capacity to estimate surface soil moisture: Two-year results over the Naizin watershed. Water Resources Research 31, 975-982

Davis, J.L., Annan, A.P., 2002. Ground penetrating radar to measure soil water content. p. 446-463. In: J.H. Dane and G.C. Topp (ed.) Methods of soil analysis. Part 4. SSSA Book Ser. 5. SSSA, Madison, WI

Doolittle, J.A., Minzenmayer, F.E., Waltman, S.W., Benham, E.C., Tuttle, J.W., Peaslee, S., 2006. State ground-penetrating radar soil suitability maps. Proceedings of the $11^{\text {th }}$ International Conference on Ground Penetrating Radar, June 19-22, Columbus Ohio, USA

Du, S., Rummel, P., 1996. Reconaissance studies of moisture in the subsurface with GPR. Proceedings of the $5^{\text {th }}$ International Conference on Ground Penetrating Radar, Kitchener, Ontario, Canada, 1241-1248

D’Urso, G., Minacapilli, M., 2006. A semi-empirical approach for surface soil water content estimation from radar data without a-priori information on surface roughness. Journal of Hydrology 321, 297-310

Evett, S.J., 2000. Some aspects of time domain reflectrometry (TDR), neutron scattering and capacitance methods of soil water content measurements, In: Comparison of soil water measurement using the neutron scattering, time domain reflectrometry and capacitance methods. IAEA-TECDOC-1137, IAEA, Vienna, Austria, 5-49

Evett, S.J., Steiner, J.L., 1995. Precision of neutron scattering and capacitance type soil water content gauges from field calibration. Soil Science Society of America Journal 59, 961-968

Ferré, P.A., Knight, J.H., Rudolph, D.L., Kachanowski, R.G., 1998. The sampling areas of conventional and alternative time domain reflectrometry probes. Water Resources Research 34, 2971-2979

Famigliette, J.S., Devereaux, J.A., Laymon, C.A., Tsegaye, T., Houser, P.R., Jackson, T.J. Graham, S.T., Rodell, M., van Oevelen, P.J., 1999. Ground based investigation of soil moisture variability within remote sensing footprints during the Southern Great Plains 1997 (SGP97) Hydrology Experiment. Water Resources Research 35, 1839-1851

Galagedara, L.W., Redman, J.D., Parkin, G.W., Annan, A.P., Endres, A.L., 2005. Numerical modeling of GPR to determine the direct ground wave sampling depth. Vadose Zone Journal 4, 1096-1106

Grote, K., Hubbard, S., Rubin, Y., 2003. Field-scale estimation of volumetric water content using ground-penetrating radar ground wave techniques. Water Resources Research 39, 13211335 
Hubbard, S., Grote, K., Rubin, Y., 2002. Mapping the volumetric soil water content of a California vineyard using high-frequency GPR ground wave data. The Leading Edge 21, 552559

Huisman, J.A., Sperl, C., Bouten, W., Verstraten, J.M., 2001. Soil water content measurements at different scales: accuracy of time domain reflectrometry and groundpenetrating radar. Journal of Hydrology 245, 48-58

Huisman, J.A., Hubbard, S.S., Redman, J.D., Annan, P.A., 2003a, Measuring soil water content with ground penetrating radar: A review. Vadose Zone Journal 2, 476-491

Huisman, J.A., Snepvangers, J.J.J.C., Bouten, W., Heuvelink, G.B.M., 2003b. Monitoring temporal development of spatial soil water content variation: Comparison of groundpenetrating-radar and time domain reflectrometry. Vadose Zone Journal 2, 519-529

Hupet, F., Vanclooster, M., 2002. Intraseasonal dynamics of soil moisture variability within a small agricultural maize cropped field. Journal of Hydrology 261, 86-101

Jackson, T.J., Le Vine, D.E., 1996. Mapping surface soil moisture using an aircraft-based passive microwave instrument: Algorithm and example, Journal of Hydrology 184, 85-99

Lambot, S., Slob, E.C., van den Bosch, I., Stockbroeckx, B., Scheers, B., Vanclooster, M., 2004a. Estimating soil electric properties from monostatic ground-penetrating radar signal inversion in the frequency domain. Water Resources Research 40, W04-205, Doi: 10.1029/2003WR002 095

Lambot, S., Slob, E.C., van den Bosch, I., Stockbroeckx, B., Vanclooster, M., 2004b. Modeling of ground-penetrating radar for accurate characterization of subsurface electric properties. IEEE Transaction on Geoscience and Remote Sensing 42, 2555-2568

Lambot, S., Rhebergen, J., van den Bosch, I., Slob, E.C., Vanclooster, M., 2004c. Measuring the soil water content profile of a sandy soil with off-ground monostatic ground penetrating radar. Vadose Zone Journal 3, 1063-1071

Lambot, S., Weihermüller, L., van den Bosch, I., Vanclooster, M., Slob, E.C., 2005. Fullwave inversion of off-ground monostatic GPR signal focused on the surface reflection for identifying surface dielectric permittivity. In: Lambot S., Gorriti, A.G., (Eds), Proceedings of the $3^{\text {rd }}$ International Workshop on Advanced Ground Penetrating Radar (IWAGPR). May 2 4, Delft, Netherlands, 113-118

Lambot, S., Weihermüller, L., Huisman, J.A., Vereecken, H., Vanclooster, M., Slob, E.C., 2006a. Analysis of air-launched ground-penetrating radar techniques to measure the soil surface water content, Water Resources Research 42, W11403, doi:10.1029/2006WR005097

Lambot, S., Antoine, M., Vanclooster, M., Slob, E.C., 2006b. Effect of soil roughness on the inversion of off-ground monostatic GPR signal for noninvasive quantification of soil properties. Water Resources Research 42: W3403, Doi: 10.1029/2005WR004416

Lunt, I.A., Hubbard, S., Rubin, Y., 2005. Soil moisture content estimation using groundpenetrating radar reflection data. Journal of Hydrology 307, 254-269

Merz, B., Bardossy, A., 1998. Effect of spatial variability on the rainfall runoff process in a small loess catchment. Journal of Hydrology 212, 304-317 
Pauwels, V.R.N., Hoeben, R., Verhoest, N.E.C., De Troch, F.P., 2001. The importance of the spatial patterns of remotely sensed soil moisture in the improvement of discharge predictions for small-scale basins through data assimilation. Journal of Hydrology 251, 88-102

Redman, J.D., Davis, J.L., Galagedara, L.W., Parkin, G.W., 2002. Field studies of GPR air lunched surface reflectivity measurements of soil water content. Proc. of the $9^{\text {th }}$ Conference of Ground-Penetrating Radar. Proc. SPIE 4758, 156-161

Ritsema, C.J., Dekker, L.W., 1998, Three-dimensional patterns of moisture, water repellency, bromide and $\mathrm{pH}$ in a sandy soil. Journal of Contaminant Hydrology 31, 295-313

Schlesinger, W., Reynolds, J., Cunningham, G., Huenneke, L., Jarrell, W., Virginia, R., Whitford, W., 1990. Biological feedbacks in global desertification. Science 24, 1043-1048

Serbin, G. Or, D., 2004. Ground-penetrating radar measurement of soil water content dynamics using a suspended horn antenna. IEEE Transaction on Geoscience and Remote Sensing 42, 1695-1705

Topp, G.C., Davis, J.L., Annan, A.P., 1980. Electromagnetic determination of soil water content: Measurements in coaxial transmission lines. Water Resources Research 16, 574-582

Ulaby, F.T., Dubois, P.C. van Zyl, J., 1996. Radar mapping of surface soil moisture. Journal of hydrology $184,57-84$

van Overmeeren, R.A., Sariowan, S.V., Gehrels, J.C., 1997. Ground penetrating radar for determining volumetric soil water content; results of comparative measurements at two sites. Journal of Hydrology 197, 316-338

Weiler, K.W., Steenhuis, T.S., Boll, J., Kung, K.-J.S., 1998. Comparison of ground penetrating radar and time domain reflectrometry as soil water sensors. Soil Science Society of America Journal 62, 1237-1239

Western, A.W., Grayson, R.B., 1998. The Tarrawarra data set: Soil moisture patterns, soil characteristics, and hydrological flux measurements. Water Resources Research 34, 2765 2768

Western, A.W., Blöschel, G., Grayson, R.B., 1998. Geostatistical characterization of the Borden aquifer. Water Resources Research 27, 533-546

Wollschläger, U., Roth, K., 2005. Estimation of temporal changes of volumetric soil water content from ground-penetrating-radar reflections. Subsurface Sensing Technologies and Applications 6, 207-218

Wood, E.F., 1997. Effects of soil moisture aggregation on surface evaporation fluxes. Journal of Hydrology 190, 397-412 